\title{
Novel Peptide Conjugates of Modified Oligonucleotides for Inhibition of Bacterial RNase P
}

\begin{abstract}
Darya Novopashina ${ }^{1,2 *}$, Mariya Vorobyeva ${ }^{1}$, Anton Nazarov ${ }^{3}$, Anna Davydova $^{1}$, Nikolay Danilin'2, Lyudmila Koroleva ${ }^{1,2}$, Andrey Matveev', Alevtina Bardasheva', Nina Tikunova ${ }^{1,2}$, Maxim Kupryushkin ${ }^{1}$, Dmitrii Pyshnyi ${ }^{1,2}$, Sidney Altman ${ }^{4,5}$ and Alya Venyaminova ${ }^{1}$
\end{abstract}

1 Institute of Chemical Biology and Fundamental Medicine, Siberian Branch of the Russian Academy of Sciences, Novosibirsk, Russia, ${ }^{2}$ Department of Natural Sciences, Novosibirsk State University, Novosibirsk, Russia, ${ }^{3}$ Shemyakin-Ovchinnikov Institute of Bioorganic Chemistry, Russian Academy of Sciences, Moscow, Russia, ${ }^{4}$ Department of Molecular, Cellular and Developmental Biology, Yale University, New Haven, CT, United States, ${ }^{5}$ Division of Life Sciences, Arizona State University, Tempe, AZ, United States

Novel alternatives to traditional antibiotics are now of great demand for the successful treatment of microbial infections. Here, we present the engineering and properties of new oligonucleotide inhibitors of RNase $\mathrm{P}$, an essential bacterial enzyme. The series of 2'-O-methyl RNA (2'-OMe-RNA) and phosphoryl guanidine oligonucleotides were targeted to the substrate-binding region of M1 RNA subunit of the RNase P. Uniformly modified 2'-OMe RNA and selectively modified phosphoryl guanidine oligonucleotides possessed good stability in biological media and effectively inhibited RNase P. Their conjugates with transporting peptides were shown to penetrate bacterial cells (Escherichia coli and Acinetobacter baumannii) and inhibit bacterial growth.

Keywords: bacterial RNase P, inhibition of RNase P, modified oligonucleotides, oligo(2'-O-methylribonucleotides), phosphoryl guanidine oligonucleotides, peptide conjugates of oligonucleotides, penetration into bacterial cells, antibacterial activity

Darya Novopashina danov@niboch.nsc.ru

Specialty section: This article was submitted to Translational Pharmacology, a section of the journal Frontiers in Pharmacology

Received: 15 March 2019

Accepted: 24 June 2019

Published: 19 July 2019

Citation:

Novopashina D, Vorobyeva $M$, Nazarov A, Davydova A, Danilin N, Koroleva L, Matveev A,

Bardasheva A, Tikunova N, Kupryushkin M, Pyshnyi D, Altman S and Venyaminova A (2019) Novel

Peptide Conjugates of Modified

Oligonucleotides for Inhibition of Bacterial RNase P.

Front. Pharmacol. 10:813 doi: 10.3389/fphar.2019.00813

\section{INTRODUCTION}

The design of novel compounds with antibacterial activity is one of the most acute issues of modern chemical biology, biotechnology, and medicine. Despite a broad spectrum of antimicrobial agents, the problems of the drug resistance and side effects remain unsolved until now (Guidry et al., 2014; Llor and Bjerrum, 2014). A promising strategy to overcome these problems could be a displacement of low-molecular-weight antimicrobial compounds targeting essential bacterial biomolecules and pathways for nucleic acid-based therapeutics targeting bacterial nucleic acids. Within this context, the development of oligonucleotides that specifically interact with bacterial RNAs, block their functions, and thereby inhibit bacterial growth is of particular interest (Bai et al., 2010). Bacterial RNase P, a tRNA-processing enzyme, is an attractive target for the design of antibacterial oligonucleotides (Guerrier-Takada et al., 1983; Altman, 2011). On the one side, RNase P is a key player of the well-established EGS (external guide sequence) technology (see, e.g., the reviews Davies-Sala et al., 2015; Derksen et al., 2015). Specially designed EGS oligonucleotides mimicking the 3'-fragment of the pre-tRNA substrate can address the enzyme to cleave the target sequence within specific bacterial mRNA. On the other side, as one of the essential bacterial enzymes, RNase P itself represents an attractive target for antibacterial agents. The enzyme contains an RNA subunit (catalytic M1 RNA), which gives a possibility to inhibit 
RNase P by complementary oligonucleotides and thus suppress the bacterial growth (Gruegelsiepe et al., 2006). One of the main advantages of this approach is the specific targeting of bacterial cells provided by huge differences between eukaryotic and bacterial enzymes, primarily their M1 RNA sequences (Klemm et al., 2016). Oligonucleotide inhibitors targeted to the bacterial RNase P should not cause any off-target effects on eukaryotic cells. The possibility of bacterial growth suppression by RNA, DNA, locked nucleic acid (LNA), and peptide nucleic acid (PNA) oligonucleotide inhibitors targeting certain M1 RNA regions was demonstrated earlier (Gruegelsiepe et al., 2003; Willkomm et al., 2003; Gruegelsiepe et al., 2006).

With all significant achievements in the design of oligonucleotide inhibitors of RNase P, there is plenty room for improvement of the resistance of these oligonucleotides to nuclease digestion and effectivity of their interaction with the enzyme, as well as penetration into bacterial cells.

Here, we present the design of novel modified oligonucleotides as RNase P inhibitors. A set of 2'-OMe-RNA and selectively modified phosphoryl guanidine oligonucleotides were generated and evaluated for their inhibiting properties. Conjugates of most prominent modified oligonucleotides with cell-penetrating peptides were shown to be capable of penetrating bacterial cells and suppress their growth.

\section{MATERIALS AND METHODS}

Tris(hydroxymethyl)aminomethane (Sigma-Aldrich, USA), acetonitrile (PanReac, Spain), acrylamide, N,N'methylenebisacrylamide (Acros Organics, Belgium), sodium perchlorate, ammonium persulfate, "Stains-All" dye, magnesium chloride, urea, xylene cyanol FF, bromophenol blue, potassium chloride (Fluka, Switzerland), $\mathrm{Na}_{2}$ EDTA (AMRESCO, USA), fetal bovine serum (FBS, heat-inactivated, Invitrogen, USA), culture medium DMEM (Life Technologies, USA), $\gamma-\left[{ }^{32} \mathrm{P}\right]-$ ATP (120 TBq/mol, «Biosan», Russia), and other reagents and solvents supplied by Sigma-Aldrich, PanReac, and Acros Organics. 3-Maleimidopropanoic acid pentafluorophenyl ester (MPPf) was synthesized by analogy with Kida et al. (2007). Peptides bearing cysteine at $\mathrm{N}$-terminus were obtained from Almabion (Russia): Pept1-CKWKLFKKIGAVLKVLTTG, Pept2-CRGW EVLKYWWNLlQY, Pept3-СНННННННННННННННН, and Pept4-CINVLGILGLLGEALSEL.

C5 protein unit of Escherichia coli RNase P was prepared as described in Guerrier-Takada et al. (1983) and kindly provided by Prof. Khodyreva S.N. (ICBFM SB RAS, Novosibirsk, Russia); M1 RNA was synthesized by protocol (Guerrier-Takada et al., 1989) and kindly provided by Prof. Moor N.A. (ICBFM SB RAS, Novosibirsk, Russia). The DH5a strain of E. coli and the type ATCC (\#19606) strain of Acinetobacter baumannii from the collection of thermophilic organisms and type cultures of ICBFM SB RAS were used for investigation of cell penetration and suppression of bacterial growth.

The radioactive $5^{\prime}$-[ $\left.{ }^{32} \mathrm{P}\right]$-labeling of oligonucleotides was performed using four $\mathrm{MBq}\left[\gamma^{-32} \mathrm{P}\right]-\mathrm{ATP}$ and T4 Polynucleotide Kinase (Thermo Scientific, USA) by standard protocol. The isolation of $5^{\prime}-\left[{ }^{32} \mathrm{P}\right]$-labeled oligonucleotides was performed with Micro Bio-Spin P30 columns (Bio-Rad, USA).

The gels were dried using Gel Dryer B35 instrument (Bio-Rad, USA) and radioautographed using Bio-Rad Exposure Cassette-K and photosensitive Kodak Storage Phosphor Screen SO230 (Bio-Rad, USA). The screen was scanned using Pharos FX (BioRad Laboratories Inc., CA, USA) Phosphorimager; the images acquired were processed using Quantity One Analysis Software (Bio-Rad Laboratories Inc., CA, USA).

Fluorescence was measured in microplates Costar 96-Well HalfArea Black (Thermo Fisher Scientific, USA) using CLARIOstar instrument (BMG LABTECH, USA).

Water filtration system simplicity (Millipore, USA), spectrophotometer NanoDrop 1000 (Thermo Fisher Scientific, USA), thermomixers and centrifuges (Eppendorf, Germany), Speed-Vac Concentrator SVC-100H (Savant, USA), the gelelectrophoresis system (Helicon, Russia), and gel-documentation system Molecular Imager FX (Bio-Rad, USA) were also used.

\section{Synthesis of Modified Oligonucleotides and Model RNA Target}

Synthesis of modified oligonucleotides and model RNA target was carried out by the solid-phase phosphoramidite method on the ASM-800 synthesizer (Biosset, Russia) using protocols optimized for this instrument. 2'-O-tert-Butyldimethylsilyl (2'-O-TBDMS) protected RNA phosphoramidites, 2'-O-methyl RNA, and DNA phosphoramidites; solid supports with first nucleosides, modified solid supports for the synthesis of 3'-fluorescein; 3'-BHQ (Black Hole Quencher), and 3'-amino linker (aminohexanol) containing oligonucleotides were purchased from ChemGene (USA). Fluorescein phosphoramidite (Glen Research, USA) was used for the introduction of fluorescein residue on 5 '-end of oligomers. DMS(O)MT-protected amino linker C6 (Lumiprobe, Russia) was used to prepare oligonucleotides bearing 5'-amino linker. Phosphoryl guanidine oligonucleotides were prepared in LLC «NooGene» (Russia) using protocols published earlier (Kupryushkin et al., 2014; Stetsenko et al., 2014).

All oligonucleotides and their derivatives were deblocked by standard protocols for the corresponding type of modification. Isolation of oligoribonucleotides, their modified analogs, and derivatives was performed using preparative electrophoresis in denaturating 15\% PAAG. Oligodeoxyribonucleotides and phosphoryl guanidine oligonucleotides were isolated by highperformance liquid chromatography (HPLC) on Agilent 1200 HPLC system (Agilent Technologies, USA) using Zorbax SB-C18 $(4.6 \times 150 \mathrm{~mm})$ column in acetonitrile concentration gradient $0-50 \%$ in $20 \mathrm{mM}$ triethylammonium acetate ( $\mathrm{pH} 7.0)$ during 30 $\mathrm{min}$ and rate $2 \mathrm{ml} / \mathrm{min}$.

\section{Investigation of the Cleavage of Modified Oligonucleotides by Serum Nucleases}

The treatment of 5'-[32 P]-labeled oligonucleotides (r-inh, $\mathbf{m}$-inh, d-inh) by $10 \%$ FBS in DMEM was carried out at $37^{\circ} \mathrm{C}$. The $5-\mu \mathrm{l}$ aliquots were taken after 15, 30,60, 120, 240, and $360 \mathrm{~min}$ and 1 day, mixed with Stop Mix solution and analyzed by denaturating $15 \%$ polyacrylamide gel electrophoresis (PAGE). 


\section{Mass Spectrometry of Oligonucleotides and Their Peptide Conjugates}

The mass spectra of the oligonucleotide conjugates were recorded on a Matrix-Assisted Laser Desorption Ionisation-Time-ofFlight (MALDI-TOF) Autoflex Speed mass-spectrometer (Bruker Daltonics, Germany). The mass spectra of phosphoryl guanidine oligonucleotides were obtained using Electrospray Ionisation Mass Spectrometry (ESI-MS) on the Agilent G6410A LC-MS/MS instrument (Agilent Technologies, USA).

\section{Hydrolysis of RNA Target by RNase P}

The hydrolysis of fluorescent RNA target (5'-flupGUUUUCUUCGGUGGGGUUUCUUCCCCACCACCABHQ-3') at a concentration from 50 to $300 \mathrm{nM}$ was carried out in $50 \mu \mathrm{l}$ of a solution containing $10 \mathrm{mM}$ Tris- $\mathrm{HCl}(\mathrm{pH} 7.5), 10 \mathrm{mM}$ $\mathrm{MgCl}_{2}, 100 \mathrm{mM} \mathrm{NH}_{4} \mathrm{Cl}, 5 \mathrm{nM} \mathrm{M} 1 \mathrm{RNA}$, and $50 \mathrm{nM}$ of C5 protein at $37^{\circ} \mathrm{C}$. RNA target was annealed for $2 \mathrm{~min}$ at $90^{\circ} \mathrm{C}$ and cooled up to $37^{\circ} \mathrm{C}$. The RNA target solution was placed in the wells of Costar 96 Half-Area Microplate. The reaction was initiated by addition of the mixture of enzyme and inhibitor oligonucleotide. Fluorescence intensity was registered each minute using CLARIOstar instrument. The excitation wavelength was $483 \mathrm{~nm}$, and the emission wavelength was $530 \mathrm{~nm}$. The data were processed using Mars Data Analysis Software (BMG Labtech, USA).

\section{Calculation of Kinetic Parameters of Hydrolysis of Fluorescent RNA Target by RNase $P$ in the Presence of Inhibiting Oligonucleotides}

The dependence of fluorescence intensity data from time was analyzed using the equation (1) in GraphPad Prism 5.0.4.533 software:

$$
F=F_{p l}\left(1-e^{k_{o b s} \cdot t}\right)
$$

where $F$ is the intensity of fluorescence on $530 \mathrm{~nm}$ at the moment $t, F_{p}$ is the fluorescence intensity upon stage (stable) phase, $k_{o b s}$ is the pseudo-first order rate constant, and $t$ is the reaction time. The values of $k_{o b s}$ were used to calculate parameters $K_{\mathrm{m}}$ and $V_{\max }$ using equation (2) in the same software package.

$$
k_{o b s}=\frac{V_{\max }}{K_{m}+S}
$$

where $V_{\max }$ is the maximum reaction rate, $K_{\mathrm{m}}$ is the Michaelis constant, and $S$ is the substrate concentration. The $k_{\text {cat }}$ value was calculated from the relationship $V_{\max }=k_{\text {cat }} \cdot E_{0}$, where $E_{0}$ is the enzyme concentration.

The $I C_{50}$ values were calculated using observed rate constants $k_{\text {obs }}$ and equation (3) for the concurrent inhibition in the same software package

$$
k_{o b s}=\frac{\left(\frac{K i}{K_{m}}\right) V_{\max }}{I C_{50}+I}
$$

$k_{o b s}$ is the pseudo-first order rate constant, Vmax is the maximal rate of reaction, $I C_{50}$ is the half-maximal inhibitory concentration, $K_{i}$ is the constant of the inhibition, $K_{m}$ is the Michaelis constant, and $I$ is the concentration of inhibiting oligonucleotide.

\section{Synthesis of Peptide Conjugates of Inhibiting Oligonucleotides}

The solution of MPPf $(1 \mathrm{mg}, 3 \mu \mathrm{mol})$ in $20 \mu \mathrm{l}$ of DMSO was added to the solution of 5' - or 3'-amino-modified oligonucleotides ( $\mathbf{m}$-inh or pgd-inh3) (120 nmol) in $5 \mu \mathrm{l}$ of $0.02 \mathrm{M}$ (4-(2-hydroxyethyl)-1piperazineathanesulfonic acid)(HEPES) ( $\mathrm{pH} 7.2$ ) by portions of 10,5 , and $5 \mu \mathrm{l}$ each $30 \mathrm{~min}$. The reaction mixture was incubated at $37^{\circ} \mathrm{C}$ upon mixing at $1,200 \mathrm{rpm}$. After $30 \mathrm{~min}$ from the last addition of MPPf, the reaction mixture was precipitated by $2 \%$ $\mathrm{NaClO}_{4}$ in acetone, and the pellet was washed by acetone and dried in air. The precipitate was dissolved in $10 \mu \mathrm{l}$ of $0.01 \mathrm{M}$ HEPES (pH 7.2). The solution of the peptide (Pept1, Pept2, Pept3, or Pept4) in $20 \mu \mathrm{l}$ of dimethylsulfoxide (DMSO) was added to the maleimide-modified oligonucleotide solution, and the reaction was carried out for $1-3 \mathrm{~h}$ at $37^{\circ} \mathrm{C}$ upon mixing at $1,200 \mathrm{rpm}$. The conjugates were isolated by electrophoresis in denaturating 12\% PAAG (acrylamide:bisacrylamide, 30:0,5), eluted by 0.3 $\mathrm{M} \mathrm{NaClO}$, and desalted using Amicon 3K (Millipore, USA). Conjugates were precipitated as $\mathrm{Na}^{+}$salts.

\section{Investigation of Conjugate Penetration to the Bacterial Cells}

Cell penetration studies were carried out at the cultures of $E$. coli and A. baumannii. The night culture of bacterial cells was diluted at 100 times by growth medium LB (lysogeny broth, Luria-Bertani medium); then, the cells $\left(3-5 \times 10^{6}\right.$ cells per $\left.\mathrm{ml}\right)$ were incubated for $2 \mathrm{~h}$ at $37^{\circ} \mathrm{C}$ upon swinging up to the optical density $\mathrm{OD}_{600}=0.35$. The cell culture was prepared at the exponential phase of growth $\left(5-6 \times 10^{6} \mathrm{cells} / \mathrm{ml}\right)$. Then cells were precipitated by centrifugation at $4,000 \times \mathrm{g}$ for $4 \mathrm{~min}$, and resuspended at LB medium containing peptide conjugate. The final concentrations of conjugates in the medium were 1 or $0.2 \mu \mathrm{M}$. The cells were incubated for $1 \mathrm{~h}$ at $37^{\circ} \mathrm{C}$ upon swinging in the dark. The cells were precipitated by centrifugation at $4,000 \times \mathrm{g}$ for $4 \mathrm{~min}$; then, $100 \mu \mathrm{l}$ of $0.9 \% \mathrm{NaCl}$ solution was added to precipitate, and the procedure was repeated twice. The cell precipitate was resuspended in $100 \mu \mathrm{l}$ of $4 \%$ formaldehyde solution in phosphate buffer and incubated for $30 \mathrm{~min}$ at room temperature upon swinging. Then, the cells were washed three times by sterile phosphate buffer and incubated with 4',6-diamidino-2-phenylindole (DAPI) for additional $15 \mathrm{~min}$.

The slides were prepared by placing $10 \mu \mathrm{l}$ of cell suspension and $10 \mu \mathrm{l}$ of antifade diamond solution (Life Technologies, USA) and covering with the $25 \times 25-\mathrm{mm}$ cover glass. Visualization was performed using the confocal laser-scanning microscope LSM 710 Carl Zeiss upon magnification at 630 times and excitation at $405 \mathrm{~nm}$ for DAPI and $488 \mathrm{~nm}$ for fluorescein isothiocyanate (FITC) (fluorescein). The pictures were analyzed with ZEN 2011 Black Edition software.

Flow cytometry was performed using the NovoCyte Instrument (ACEA Biosciences, USA). 


\section{Bacterial Growth Inhibition Experiments}

Oligonucleotides and their conjugates were tested for inhibition of bacterial cell growth using E. coli (strain DH5a). Cell cultures were incubated with the oligonucleotide or oligonucleotidepeptide conjugate for $22 \mathrm{~h}$ in 96 -well plate at $37^{\circ} \mathrm{C}$ and rotation at $530 \mathrm{rpm}$. In control samples, water was used instead of the conjugate solution. The growth of cultures was estimated by optical density at $595 \mathrm{~nm}$ using plate reader (Uniplan, Russia).

\section{RESULTS AND DISCUSSION}

To study the RNase P activity in the presence of oligonucleotide inhibitors, we employed the model synthetic hairpin RNA imitating the natural pre-tRNA substrate of RNase P. This RNA contained 5'-fluorescein and 3'-BHQ quencher residues (Figure 1).

Upon the RNA hydrolysis, fluorophore and quencher are moving away from each other, and the fluorescence arises. The values of the kinetic parameters for the hydrolysis of fluorescent RNA target by $E$. coli RNase $\mathrm{P}\left(K_{\mathrm{m}}=83 \pm 49 \mathrm{nM}, k_{\text {cat }}=24 \pm 5 \mathrm{~min}^{-1}\right.$, see Figure S1, Table S1) are close to those for the hydrolysis of the native pre-tRNA ${ }^{\mathrm{Tyr}}\left(K_{\mathrm{m}}=33 \mathrm{nM}, k_{\text {cat }}=29 \mathrm{~min}^{-1}\right.$ ) (Jiang et al., 2014). Therefore, we validated the appropriate catalytic activity of the enzyme and the feasibility of fluorescent RNA as a model substrate. The presence of fluorescent and quencher groups had no impact on the affinity of the substrate to the enzyme and the cleavage rate.

One of the most suitable sites for RNase P inhibition is the region of P15 loop taking part in recognition of CCA sequence on the 3'-end of the pre-tRNA substrate (Childs et al., 2003; Gruegelsiepe et al., 2003; Willkomm et al., 2003). Modified oligomers complementary to the 291-304 fragment of E. coli M1 RNA and containing 2'-O-methylated or LNA monomers specifically inhibited $\mathrm{RNase} P$ with practically the same $\mathrm{IC}_{50}$ values (Childs et al., 2003). PNA conjugates with peptides suppressed $E$. coli growth in cell culture experiments (Gruegelsiepe et al., 2006).

Based on these data, we designed 14-nt oligonucleotide inhibitors complementary to nucleotides 291-304 in the P15-loop (Figure 2, Table 1). The set of inhibitors included native oligoribonucleotide, oligo(2'-O-methylribonucleotide), oligodeoxyribonucleotide, and oligodeoxyribonucleotides with phosphoryl guanidine modifications in different positions.

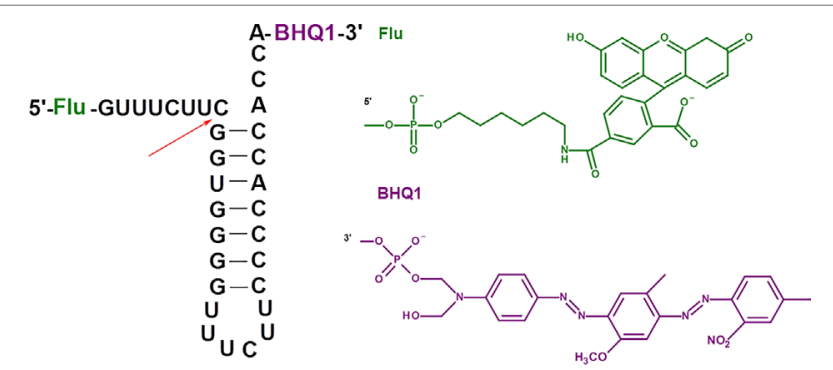

FIGURE 1 | Model fluorescent RNA target for the investigation of inhibition of RNase P. The arrow shows the site of RNA hydrolysis.

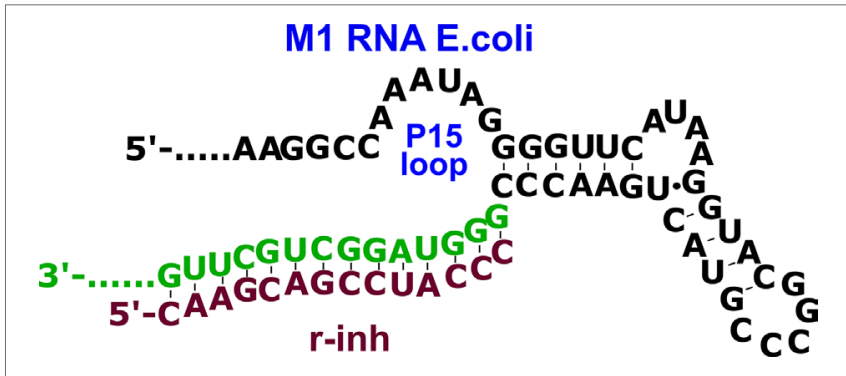

FIGURE 2 | The complex of oligoribonucleotide inhibitor (r-inh) with P15 loop region of the M1 RNA E. coli.

TABLE 1 | The inhibiting oligonucleotides and $I_{50}$ values for hydrolysis of RNA target.

\begin{tabular}{|c|c|c|}
\hline Inhibitor & Sequence, 5'-3' & $\mathrm{IC}_{50}, \mathrm{nM}$ \\
\hline r-inh & 5'-r(CAAGCAGCCUACCC) & $12 \pm 4$ \\
\hline m-inh & $5^{\prime}-C^{m} A^{m} A^{m} G^{m} C^{m} A^{m} G^{m} C^{m} C^{m} U^{m} A^{m} C^{m} C^{m} C^{m}$ & $90 \pm 30$ \\
\hline d-inh & 5'-d(CAAGCAGCCTACCC) & $270 \pm 90$ \\
\hline pgd-inh1 & 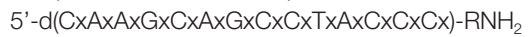 & No effect \\
\hline pgd-inh2 & 5'-d(CxAxAxGxCxAxGxCCTACCC) & $400 \pm 100$ \\
\hline pgd-inh3 & 5'-d(CAAGCAGCxCxTxAxCxCxC) & $100 \pm 40$ \\
\hline
\end{tabular}

The cleavage conditions: 5 nM M1 RNA, 50 nM C5 protein, 100 nM fluorescent RNA target, 0-125 nM inhibiting oligonucleotide, $10 \mathrm{mM}$ Tris- $\mathrm{HCl}, \mathrm{pH} 7.5,10 \mathrm{mM} \mathrm{MgCl}_{2}$, $100 \mathrm{mM} \mathrm{NH}_{4} \mathrm{Cl}, 37^{\circ} \mathrm{C}$. $\mathrm{N}^{\mathrm{m}}-2^{\prime}$-O-methylribonucleotide; $\mathrm{Nx}$ - phosphoryl guanidine deoxyribonucleotide; $x$ - phosphate groups modified with 1,3-dimethylimidazolidine-2imine residues, $\mathrm{RNH}_{2}=-\left(\mathrm{CH}_{2}\right)_{6} \mathrm{NH}_{2}$. The results represent mean values ( $\pm \mathrm{SD}$ ) from two independent experiments.

Figure 3 shows the typical curves for hydrolysis of fluorescent RNA target upon inhibition of RNase P by r-inh. We observed the progressive decrease of enzyme activity upon the increase of the inhibitor concentration. The values of the half-maximal inhibitory concentration $\left(\mathrm{IC}_{50}\right)$ were obtained using the equation (3) for competitive inhibition, by analogy with (Sabatino and Damha, 2007) (Table 1).

The non-modified oligoribonucleotide $\mathbf{r}$-inh provided the maximal inhibitory effect. The change of ribose for

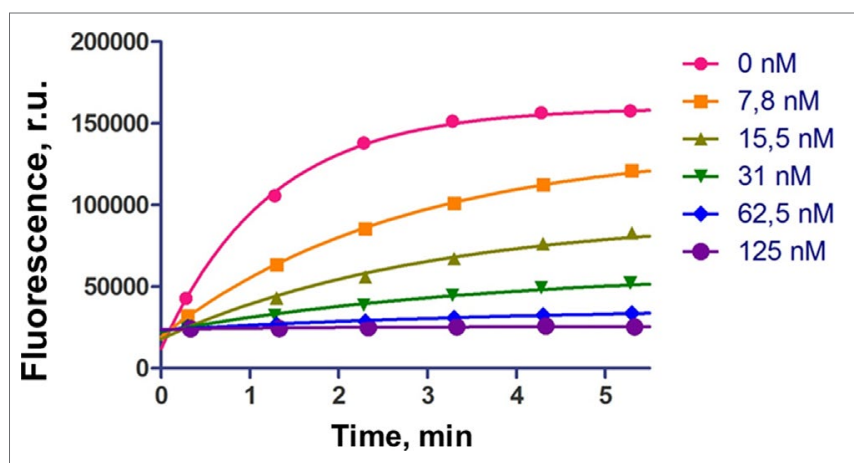

FIGURE 3 | The influence of inhibiting oligoribonucleotide $\mathbf{r}$-inh on hydrolysis of fluorescent RNA target. The cleavage conditions: 5 nM M1 RNA, 50 nM C5 protein, $100 \mathrm{nM}$ fluorescent RNA target, 0-125 nM inhibiting oligonucleotide, $10 \mathrm{mM}$ Tris- $\mathrm{HCl}, \mathrm{pH} 7.5,10 \mathrm{mM} \mathrm{MgCl}_{2}, 100 \mathrm{mM} \mathrm{NH}_{4} \mathrm{Cl}, 37^{\circ} \mathrm{C}$. 
2'-O-methylated ribose (m-inh) or deoxyribose (d-inh) led to more modest inhibiting activity: the $\mathrm{IC}_{50}$ values increased approximately 10 times. There was no inhibiting effect in the case of uniformly modified phosphoryl guanidine oligonucleotide pgdinh1. Nevertheless, selectively modified phosphoryl guanidine oligonucleotides pgd-inh2 and pgd-inh3 containing modified phosphodiester linkages in certain positions showed pronounced inhibiting activity. At that, pgd-inh3 with phosphoryl guanidinemodified 3'-terminal fragment was more effective than pgd-inh2 with the same modifications introduced close to the 5'-end. We chose two most effective modified oligonucleotide inhibitors m-inh $\left(\mathrm{IC}_{50}=90 \mathrm{nM}\right)$ and pgd-inh3 $\left(\mathrm{IC}_{50}=100 \mathrm{nM}\right)$ for further studies. These oligomers combine RNase $\mathrm{P}$ inhibiting activity with good stability in biological media (Novopashina et al., 2018) (see Figure S2), so we consider them as a prospective basis for the development of antibacterial agents. Of note, the high level of structural and functional conservation of bacterial RNase P (Altman, 2011) permits to extrapolate the regularities obtained for E.coli enzyme to the other bacterial species, particularly A. baumannii (Davies-Sala et al., 2018).

Currently, several oligonucleotide constructions have been proposed as antibacterial agents (Woodford and Wareham, 2008; Cansizoglu and Toprak, 2017; Narenji et al., 2017; Równicki et al., 2018; Xue et al., 2018; González-Paredes et al., 2019). In this context, the pivotal challenges are the resistance of oligonucleotides to the nuclease digestion, the capability to penetrate bacterial cells, and the efficiency of interaction with a target bacterial molecule. To solve the problem of cell penetration, we coupled antibacterial oligonucleotide constructs with cell delivery agents (Good, 2003; Good and Stach, 2011; Giedyk et al., 2019). Four peptides were chosen as transporters: 19-mer fragment CM18 of cecropin-A/melittin hybrid peptide capable to disturb membrane (Salomone et al., 2013; Fasoli et al., 2014); 15-mer fragment of HGP peptide of gp41 HIV protein, which enhances endosomolytic activity (Kwon et al., 2008; Kwon et al., 2010); 16-mer oligohistidine peptide $\left(\mathrm{H}_{16}\right)$ (Iwasaki et al., 2015); and 17-mer analog of bombolytine $\mathrm{V}$, membrane-destroying antimicrobial peptide (AMP), with all basic residues replaced by the glutamine acid (Ahmad et al., 2015).

For synthesizing oligonucleotide-peptide conjugates, we used the strategy based on thiol-maleimide conjugation chemistry (Figure 4). The maleimide group was attached to the 5'- or 3'-amino-modified oligonucleotide using MPPf synthesized by analogy with (Gruegelsiepe et al., 2003). The peptides containing $\mathrm{N}$-terminal cysteine reacted with the maleimide-modified oligonucleotide, giving the covalent conjugates (Table 2). The degrees of the oligonucleotides' conversion to the conjugates were about $70-90 \%$ by the HPLC data, depending on the type of the peptide. The conjugates were isolated by denaturating PAGE and analyzed by MALDI-TOF and ESI mass spectrometry (Figure S7 and S8).

For cell penetration studies, we employed 5'-peptide conjugates of oligonucleotides bearing the 3'-fluorescein label. The levels of penetration in E. coli and A. baumannii were estimated using flow cytometry (Figure 5, Table S2), and the intracellular distribution of conjugates was visualized using confocal microscopy (Figure S3, S4 and Table S3).

Fluorescent oligo(2'-O-methylribonucleotide) $\mathbf{m}$-inh-Flu penetrated E. coli cells at the level of $2 \%$. However, the levels of cell penetration were significantly higher for peptide conjugates of $\mathbf{m}$-inh-Flu. Approx. 10-12\% of oligonucleotides, depending on the peptide, were found in E. coli. Meanwhile, the levels of penetration in A. baumannii were approx. 3-6\%. Peptide conjugates of phosphoryl guanidine oligonucleotide pgd-inh3Flu demonstrated fewer levels of penetration into the bacterial cells. The best result was observed for 5'-Pept2-pgd-inh3-Flu, which penetrated A. baumannii at the level of $6.5 \%$.

The obtained results indicated that conjugation with peptides facilitates the penetration of modified oligonucleotides into bacterial cells of both types. Nearly in all cases, we observed better penetration for E. coli cells compared to A. baumannii. This phenomenon might be explained by distinct differences either in the cell wall structure or in efflux systems of these two gram-negative bacteria. Therefore, the approach to intracellular delivery requires optimization when passing from one bacterium to another, even within the same class.

The oligonucleotides and their conjugates were tested on their antibacterial properties using E. coli as a target. We used approximately $60 \mathrm{mg} / \mathrm{ml}$ concentrations of oligonucleotide inhibitors, which are comparable with the minimum inhibiting concentration (MIC) for standard antibiotics $(50-300 \mathrm{mg} / \mathrm{ml})$ (Wannigama et al., 2019). Namely, we studied conjugates of m-inh and pgd-inh3 with Pept2 peptide at the 5'-end, either with or without 3'-fluorescein residue (Figure 6), and the same oligonucleotides with Pept2 at the 3'-end. Despite the relatively low level of the cell penetration for phosphoryl guanidine oligonucleotide, we observed the suppression of E. coli growth

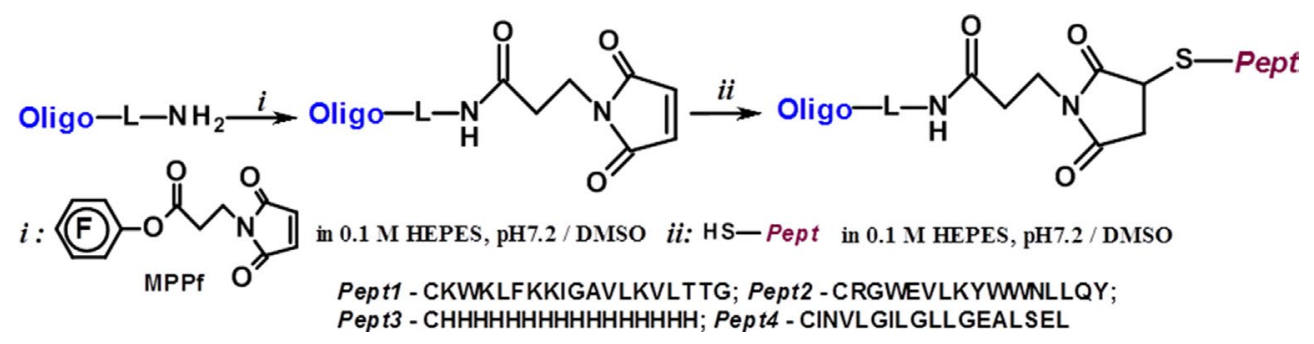

FIGURE 4 | Scheme of the synthesis of the peptide conjugates of modified oligonucleotides $\mathbf{m}$-inh and pgd-inh3. 
TABLE 2 | The peptide conjugates of RNase P inhibiting oligonucleotides $\mathbf{m}$-inh and pgd-inh3.

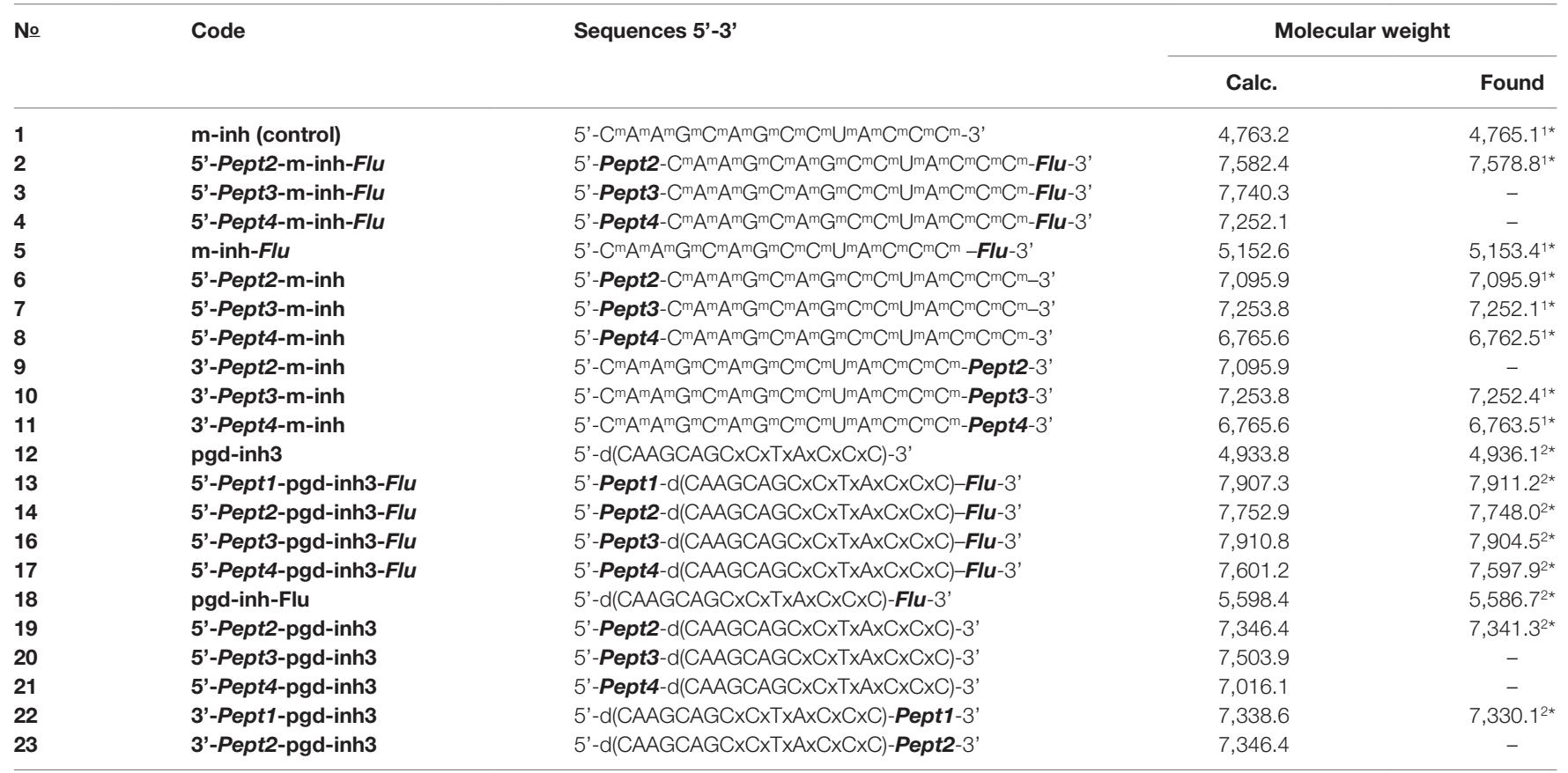

$N^{m}-A^{m}, U^{m}, C^{m}, G^{m}-2^{\prime}$-O-methylribonucleotides, Nx - phosphoryl guanidine deoxyribonucleotide, Flu - fluorescein residue, Pept1- CKWKLFKKIGAVLKVLTTG, Pept2 CRGWEVLKYWWNLLQY, Pept3 - CHHHHHHHHHHHHHHHH, Pept4 - CINVLGILGLLGEALSEL. ${ }^{*}$ - Determined by MALDI-TOF mass-spectrometry. ${ }^{2 *}$ - Determined by ESI mass-spectrometry.

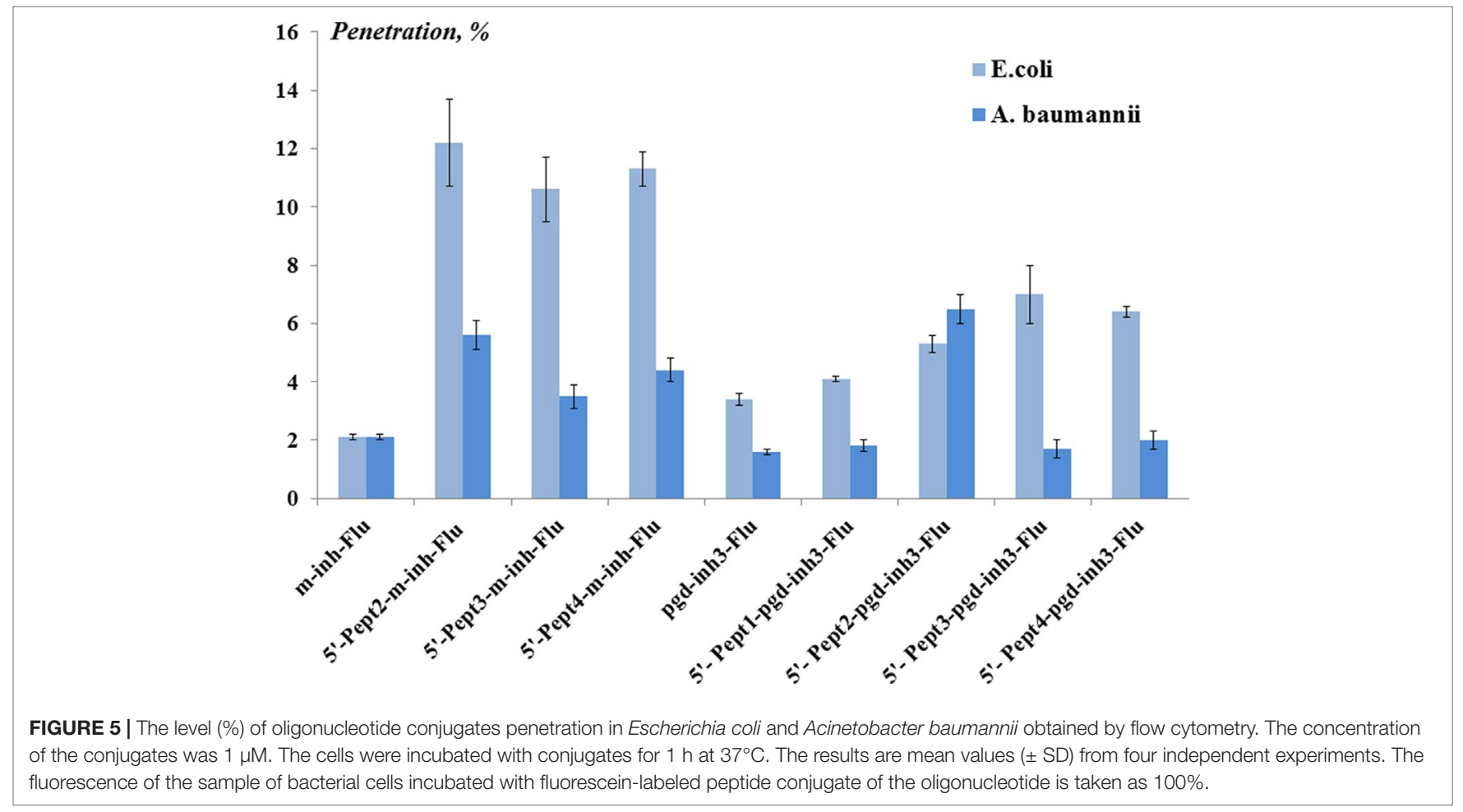



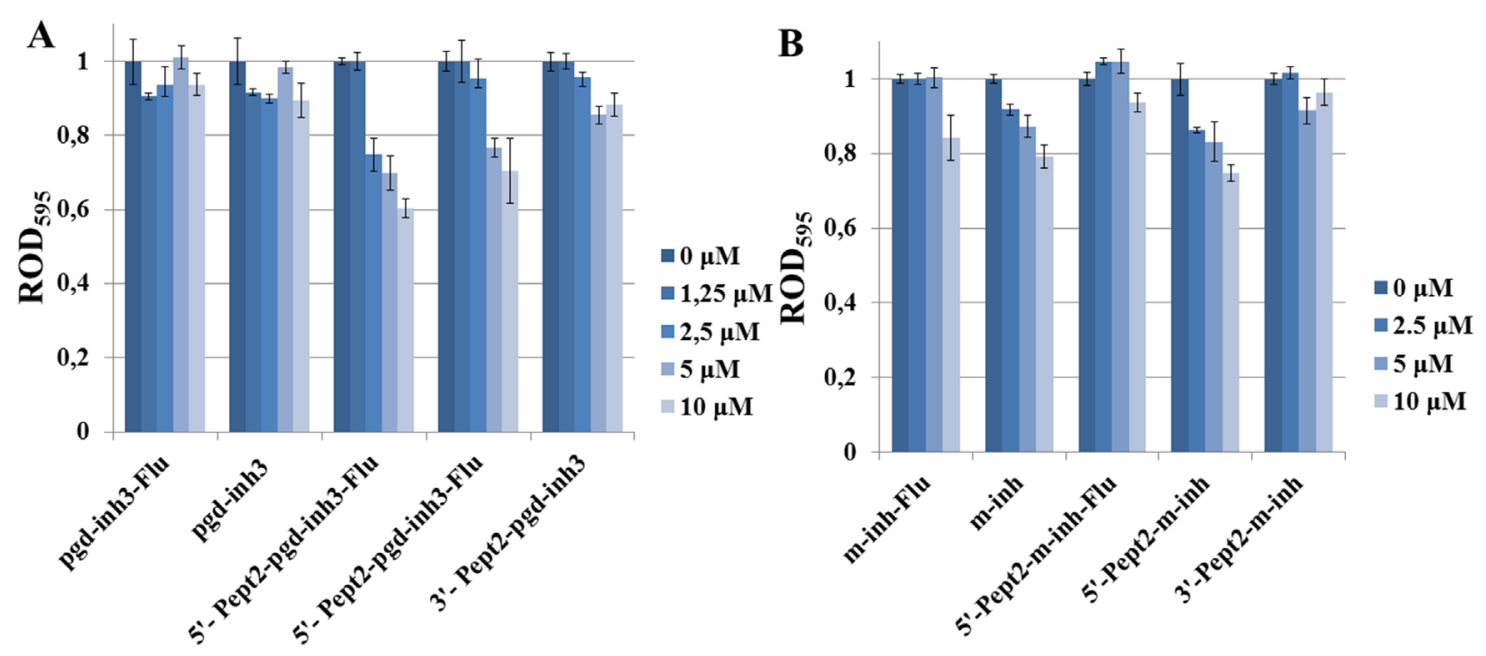

FIGURE 6 | Influence of the peptide conjugates of inhibiting phosphoryl guanidine oligonucleotide (A) and oligo(2'-O-methylribonucleotide) (B) on E. coli growth. Concentrations of conjugates in the media were $0-10 \mu \mathrm{M}$. Bacterial cells were incubated in the cell culture plate (96-well) at $37^{\circ} \mathrm{C}$ and $580 \mathrm{rpm}$ during $22 \mathrm{~h}$. $\mathrm{ROD}_{595}$-relative optical density, the ratio of $\mathrm{OD}_{495}$ for the sample and oligonucleotide-free control. Values are mean $\pm S D(n=3)$.

for 5 '-peptide conjugates, and the presence of fluorescein residue enhanced the effect to some extent (Figure 6A). Inhibiting 2'-OMe RNA oligonucleotides suppressed the bacterial growth irrespective of the absence or presence of 5'-peptide. Upon that, although their level of cell penetration was higher than that for phosphoryl guanidines, the inhibiting effect was somewhat lower as compared to peptide conjugates of pgd-inh3 (Figure 6B). For both types of modified oligonucleotides, peptide attached to the 3'-end had no impact on their inhibiting activities: unconjugated oligomers and their 3'-peptide conjugates suppressed the bacterial growth to the same extent. We suppose that the presence of bulk peptide fragment at the 3 '-end causes steric hindrance for binding of 3'-CCA fragment to M1RNA in P15 loop site. We also observed all abovementioned regularities for conjugates with the peptides Pept1, Pept3, and Pept4 (see Figure S5 and S6).

Enhancement of antibacterial effect upon attachment of peptides to the 5'-end of modified oligonucleotide inhibitors of RNase $\mathrm{P}$ proves the feasibility of the proposed approach. We had not observed any correlation between the level of cell penetration of the oligonucleotide and their ability to suppress the bacterial growth. Peptide conjugates of 2'-OMe RNA demonstrated relatively good cell penetration, but rather low antibacterial activity. Relevant conjugates of the phosphoryl guanidine oligonucleotide were less effective in cell penetration but showed better results in suppression of bacterial growth. We hypothesize that the optimization of cell-penetrating properties of phosphoryl guanidine oligonucleotides would improve their antibacterial properties. Further studies are required to prove this suggestion, directed to revealing the roles of oligonucleotide and peptide counterparts in the cell penetration and growth suppression. With this knowledge, we would be able to optimize the structure of oligonucleotide-peptide conjugates inhibiting RNase $\mathrm{P}$ to improve their antibacterial activity.

\section{DATA AVAILABILITY}

All datasets generated for this study are included in the manuscript and/or the supplementary files.

\section{AUTHOR CONTRIBUTIONS}

$\mathrm{DN}$ and $\mathrm{MV}$ conceived and designed the experiments. $\mathrm{AN}, \mathrm{AD}$, ND, LK, AM, AB, and MK performed the experiments. NT, DP, $\mathrm{SA}$, and AV analyzed the data and co-wrote the paper.

\section{FUNDING}

The research was carried out with financial support by the RFBR grant N 17-04-01892. In the part of the synthesis of modified oligonucleotides, the work was supported by the Russian State-funded budget project of ICBFM SB RAS \# AAAA-A17117020210021-7.

\section{ACKNOWLEDGMENTS}

The authors are grateful to Donna Wesolowski (Yale University, USA), who kindly provided the plasmids for the preparation of the RNase P subunits, Prof. S.N. Khodyreva for preparation and isolation of C5 protein, and Prof. N.A. Moor for preparation and isolation of M1 RNA.

\section{SUPPLEMENTARY MATERIAL}

The Supplementary Material for this article can be found online at: https://www.frontiersin.org/articles/10.3389/fphar.2019.00813/ full\#supplementary-material 


\section{REFERENCES}

Ahmad, A., Ranjan, S., Zhang, W., Zou, J., Pyykkö, I., and Kinnunen, P. K. J. (2015). Novel endosomolytic peptides for enhancing gene delivery in nanoparticles. Biochim. Biophys. Acta 1848, 544-553. doi: 10.1016/j.bbamem.2014.11.008

Altman, S. (2011). Ribonuclease P. Philos. Trans. R. Soc. B 366, 2936-2941. doi: $10.1098 /$ rstb.2011.0142

Bai, H., Xue, X., Hou, Z., Zhou, Y., Meng, J., and Luo, X. (2010). Antisense antibiotics: a brief review of novel target discovery and delivery. Curr. Drug Discov. Technol. 7, 76-85. doi: 10.2174/157016310793180594

Cansizoglu, M. F., and Toprak, E. (2017). Fighting against evolution of antibiotic resistance by utilizing evolvable antimicrobial drugs. Curr. Genet. 63, 973-976. doi: 10.1007/s00294-017-0703-x

Childs, J. L., Poole, A. W., and Turner, D. H. (2003). Inhibition of Escherichia coli RNase P by oligonucleotide directed misfolding of RNA. RNA 9, 1437-1445. doi: $10.1261 /$ rna.5780503

Davies-Sala, C., Jani, S., Zorreguieta, A., and Tolmasky, M. E. (2018). Identification of the Acinetobacter baumannii ribonuclease $\mathrm{P}$ catalytic subunit: cleavage of a target mRNA in the presence of an external guide sequence. Front. Microbiol. 9, 2408. doi: 10.3389/fmicb.2018.02408

Davies-Sala, C., Soler-Bistué, A., Bonomo, R. A., Zorreguieta, A., and Tolmasky, M. E. (2015). External guide sequence technology: a path to development of novel antimicrobial therapeutics. Ann. N. Y. Acad. Sci. 1354, 98-110. doi: 10.1111/ nyas. 12755

Derksen, M., Mertens, V., and Pruijn, G. J. (2015). RNase P-mediated sequencespecific cleavage of RNA by engineered external guide sequences. Biomolecules 5, 3029-3050. doi: 10.3390/biom5043029

Fasoli, A., Salomone, F., Benedusi, M., Boccardi, C., Rispoli, G., Beltram, F., et al. (2014). Mechanistic insight into CM18-Tat11 peptide membrane-perturbing action by whole-cell patch-clamp recording. Molecules 19, 9228-9239. doi: 10.3390/molecules 19079228

Giedyk, M., Jackowska, A., Równicki, M., Kolanowska, M., Trylska, J., and Gryko, D. (2019). Vitamin B 12 transports modified RNA into E. coli, and S. Typhimurium cells. Chem. Commun. 55, 763-766. doi: 10.1039/C8CC05064C

González-Paredes, A., Sitia, L., Ruyra, A., Morris, C. J., Wheeler, G. N., McArthur, M., et al. (2019). Solid lipid nanoparticles for the delivery of anti-microbial oligonucleotides. Eur. J. Pharm. Biopharm. 134, 166-177. doi: 10.1016/j. ejpb.2018.11.017

Good, L. (2003). Translation repression by antisense sequences. Cell. Mol. Life Sci. 60, 854-861. doi: 10.1007/s00018-003-3045-4

Good, L., and Stach, J. E. M. (2011). Synthetic RNA silencing in bacteria? Antimicrobial discovery and resistance breaking. Front. Microbiol. 2, 185. doi: 10.3389/fmicb.2011.00185

Gruegelsiepe, H., Brandt, O., and Hartmann, R. K. (2006). Antisense inhibition of RNase P. J. Biol. Chem. 281, 30613-30620. doi: 10.1074/jbc.M603346200

Gruegelsiepe, H., Willkomm, D. K., Goudinakis, O., and Hartmann, R. K. (2003). Antisense inhibition of Escherichia coli RNase P RNA: mechanistic aspects. ChemBioChem 4, 1049-1056. doi: 10.1002/cbic.200300675

Guerrier-Takada, C., Lumelsky, N., and Altman, S. (1989). Specific interactions in RNA enzyme-substrate complexes. Science 246, 1578-1584. doi: 10.1126/ science. 2480641

Guerrier-Takada, C., Gardiner, K., Marsh, T., Pace, N., and Altman, S. (1983). The RNA moiety of ribonuclease $\mathrm{P}$ is the catalytic subunit of the enzyme. Cell 35, 849-57. doi: 10.1016/0092-8674(83)90117-4

Guidry, C. A., Mansfield, S. A., Cook, C. H., and Sawyer, R. G. (2014). Resistant pathogens, fungi, and viruses. Surg. Clin. North Am. 94, 1195-1218. doi: 10.1016/j.suc.2014.08.010

Iwasaki, T., Tokuda, Y., Kotake, A., Okada, H., Takeda, S., Kawano, T., et al. (2015). Cellular uptake and in vivo distribution of polyhistidine peptides. J. Control. Release 210, 115-124. doi: 10.1016/j.jconrel.2015.05.268

Jiang, X., Sunkara, N., Lu, S., and Liu, F. (2014). Directing RNase P-mediated cleavage of target mRNAs by engineered external guide sequences in cultured cells. Methods Mol. Biol. 1103, 45-56. doi: 10.1007/978-1-62703-730-3_4

Kida, S., Maeda, M., Hojo, K., Eto, Y., Nakagawa, S., and Kawasakia, K. (2007). Studies on heterobifunctional cross-linking reagents, 6-maleimidohexanoic acid active esters. Chem. Pharm. Bull. (Tokyo) 55, 685-687. doi: 10.1248/ cpb. 55.685

Klemm, B. P., Wu, N., Chen, Y., Liu, X., Kaitany, K. J., Howard, M. J., et al. (2016). The diversity of ribonuclease P: Protein and RNA catalysts with analogous biological functions. Biomolecules 6, 27. doi: 10.3390/biom6020027

Kupryushkin, M. S., Pyshnyi, D. V., and Stetsenko, D. A. (2014). Phosphoryl guanidines: a new type of nucleic acid analogues. Acta Naturae 6, 116-118.

Kwon, E. J., Bergen, J. M., and Pun, S. H. (2008). Application of an HIV gp41-derived peptide for enhanced intracellular trafficking of synthetic gene and siRNA delivery vehicles. Bioconjug. Chem. 19, 920-927. doi: 10.1021/bc700448h

Kwon, E. J., Liong, S., and Pun, S. H. (2010). A Truncated HGP peptide sequence that retains endosomolytic activity and improves gene delivery efficiencies. Mol. Pharm. 7, 1260-1265. doi: 10.1021/mp1000668

Llor, C., and Bjerrum, L. (2014). Antimicrobial resistance: risk associated with antibiotic overuse and initiatives to reduce the problem. Ther. Adv. Drug. Saf. 5, 229-241. doi: 10.1177/2042098614554919

Narenji, H., Gholizadeh, P., Aghazadeh, M., Rezaee, M. A., Asgharzadeh, M., and Kafil, H. S. (2017). Peptide nucleic acids (PNAs): currently potential bactericidal agents. Biomed. Pharmacother. 93, 580-588. doi: 10.1016/j. biopha.2017.06.092

Novopashina, D. S., Nazarov, A. S., Vorobjeva, M. A., Kuprushkin, M. S., Davydova, A. S., Lomzov, A. A., et al. (2018). Modified oligonucleotides for guiding RNA cleavage using bacterial RNase P. Mol. Biol. 52, 905-912. doi: $10.1134 /$ S0026893318060134

Równicki, M., Pieńko, T., Czarnecki, J., Kolanowska, M., Bartosik, D., and Trylska, J. (2018). Artificial activation of Escherichia coli mazEF and hipBA toxin-antitoxin systems by antisense peptide nucleic acids as an antibacterial strategy. Front. Microbiol. 9, 2870. doi: 10.3389/fmicb.2018.02870

Sabatino, D., and Damha, M. J. (2007). Oxepane nucleic acids: synthesis, characterization, and properties of oligonucleotides bearing a seven-membered carbohydrate ring. J. Am. Chem. Soc. 129, 8259-8270. doi: 10.1021/ja071336c

Salomone, F., Cardarelli, F., Signore, G., Boccardi, C., and Beltram, F. (2013). In vitro efficient transfection by CM18-Tat11 hybrid peptide: a new tool for gene-delivery applications. PLoS One 8, e70108. doi: 10.1371/journal. pone. 0070108

Stetsenko, D. A., Kupryushkin, M. S., and Pyshnyi, D. V. (2014). Modified oligonucleotides and methods for their synthesis. International patent WO2016028187 A1

Wannigama, D. L., Hurst, C., Pearson, L., Saethang, T., Singkham-In, U., Luk-In, S., et al. (2019). Simple fluorometric-based assay of antibiotic effectiveness for Acinetobacter baumannii biofilms. Sci. Rep. 9, 6300. doi: 10.1038/s41598019-42353-0

Willkomm, D. K., Gruegelsiepe, H., Goudinakis, O., Kretschmer-Kazemi Far, R., Bald, R., Erdmann, V. A., et al. (2003). Evaluation of bacterial RNase P RNA as a drug target. ChemBioChem 4, 1041-1048. doi: 10.1002/cbic.200300674

Woodford, N., and Wareham, D. W. (2008). Tackling antibiotic resistance: a dose of common antisense? J. Antimicrob. Chemother. 63, 225-229. doi: 10.1093/jac/ dkn467

Xue, X.-Y., Mao, X.-G., Zhou, Y., Chen, Z., Hu, Y., Hou, Z., et al. (2018). Advances in the delivery of antisense oligonucleotides for combating bacterial infectious diseases. Nanomed. Nanotechnol. Biol. Med. 14, 745-758. doi: 10.1016/j. nano.2017.12.026

Conflict of Interest Statement: The authors declare that the research was conducted in the absence of any commercial or financial relationships that could be construed as a potential conflict of interest.

Copyright @ 2019 Novopashina, Vorobyeva, Nazarov, Davydova, Danilin, Koroleva, Matveev, Bardasheva, Tikunova, Kupryushkin, Pyshnyi, Altman and Venyaminova. This is an open-access article distributed under the terms of the Creative Commons Attribution License (CC BY). The use, distribution or reproduction in other forums is permitted, provided the original author(s) and the copyright owner(s) are credited and that the original publication in this journal is cited, in accordance with accepted academic practice. No use, distribution or reproduction is permitted which does not comply with these terms. 